\title{
GRAIN BOUNDARIES AND MECHANICAL PROPERTIES OF NANOCRYSTALLINE DIAMOND FILMS*
}

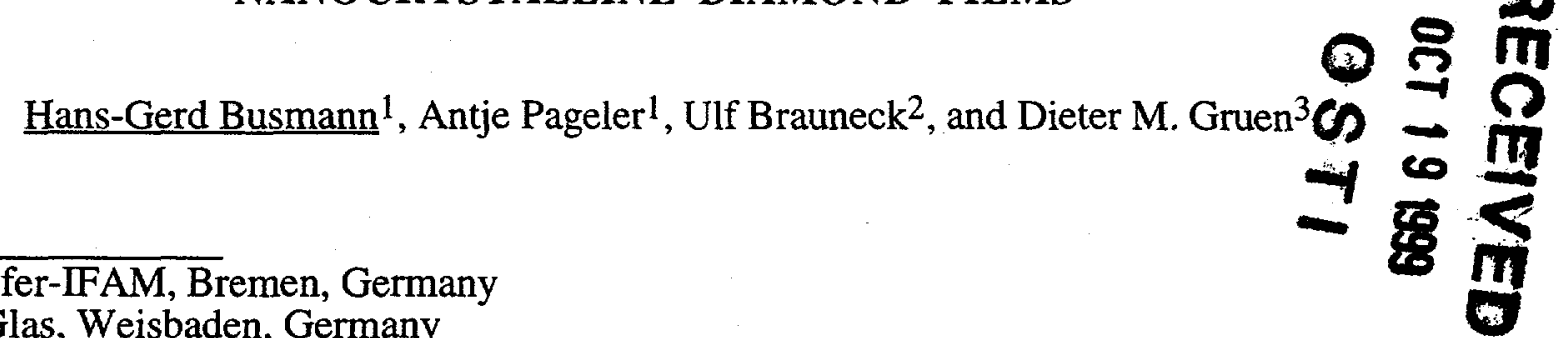

1Fraunhofer-IFAM, Bremen, Germany

${ }^{2}$ Schott Glas, Weisbaden, Germany

${ }^{3}$ Materials Science and Chemistry Divisions, Argonne National Laboratory, Argonne, IL 60439

submitted for presentation at and for the proceedings of the

International Symposium on Metastable, Mechanically Alloyed and Nanocrystalline Materials 1999 (ISMANAM-99)

Dresden, Germany

August 30-September 3, 1999

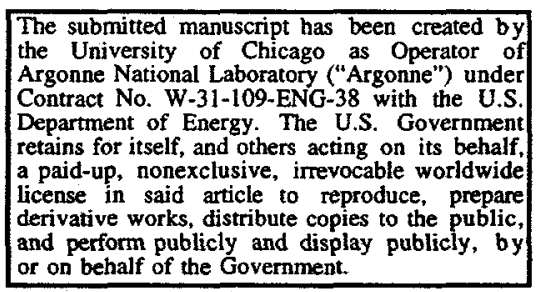

*Work supported by the U.S. Department of Energy, BES-Materials Sciences, under Contract W-31-109-ENG-38. 


\section{DISCLAIMER}

This report was prepared as an account of work sponsored by an agency of the United States Government. Neither the United States Government nor any agency thereof, nor any of their employees, make any warranty, express or implied, or assumes any legal liability or responsibility for the accuracy, completeness, or usefulness of any information, apparatus, product, or process disclosed, or represents that its use would not infringe privately owned rights. Reference herein to any specific commercial product, process, or service by trade name, trademark, manufacturer, or otherwise does not necessarily constitute or imply its endorsement, recommendation, or favoring by the United States Government or any agency thereof. The views and opinions of authors expressed herein do not necessarily state or reflect those of the United States Government or any agency thereof. 


\section{DISCLAIMER}

Portions of this document may be illegible in electronic image products. Images are produced from the best available original document. 


\title{
GRAIN BOUNDARIES AND MECHANICAL PROPERTIES OF NANOCRYSTALLINE DLAMOND FILMS
}

\author{
Hany-Gerd Busmann", Antje Pageler", Ulf Brauneck' and Dieter M. Gruenc \\ ${ }^{a}$ Fraunhofer-IFAM, Wiener Str. 12, D-28359 Bremen, Germany \\ b Schott Glas, Hagenauer Str. 38, 65203 Wiesbaden, Germany \\ 'Materials Science and Chemistry Divisions, Argonne National Laboratory, Argonne, IL 60439, USA
}

KEYWORDS: Nanocrystalline Diamond, Grain Boundaries, Hardness

\begin{abstract}
Phase-pure nanocrystalline diamond thin films grown from plasmas of a hydrogen-poor carbon argon gas mixture have been analyzed regarding their hardness and elastic moduli by means of a microindentor and a scanning acoustic microscope. The films are superhard and the moduli rival single crystal diamond. In addition, Raman spectroscopy with an excitation wavelength of $1064 \mathrm{~nm}$ shows a peak at $1438 \mathrm{I} / \mathrm{cm}$ and no peak above $1500 \mathrm{l} / \mathrm{cm}$, and X-ray phoioelectron spectroscopy a shake-up loss at 4,2 $\mathrm{eV}$. This gives strong evidence for the existence of solitary double bonds in the films. The hardness and elasticity of the films then are explained by the assumption. that the solitary double bonds interconnect the nanocrystals in the films, leading to an intergrain boundary adhesion of similar strength as the intragrain diamond cohesion. The results are in good agreement with recent simulations of high-energy grain boundaries.
\end{abstract}

\section{INTRODUCTION}

Perfect crystal diamond has outstanding properties such as hardness, optical transpareacy, and thermal conductivity. It is thus an attractive material for many applications. Plasma-assisted chemical vapor deposition (PACVD) is now widely used for the development of commercial uses of diamond thin films for tools, diaphragm, heat sinks, surface acoustic wave devices, and optical windows. Deviations of the properties of PACVD diamond films from those of perfect crystal diamond are mainly due to the microstructure of the films. Thus, the columarar grain structure and grain boundaries extending through the films tend to decrease hardness, optical transparency and thermal conductivity. Conventional diamond PACVD processes involve the use of hydrocarbon / hydrogen plasmas with a large excess of tydrogen (typically $99 \%$ ). The presence of large amounts of hydrogen is frequently cited to be mandatory for diamond vapor growth because hydrogen is said to stabilize surface radical sites thereby preventing graphitization.

Recently a new type of microwave plasma chemistry bas led to phase-pure nanocrystalline diamond (PPNCD) films with a densely packaged diamond grains with diameters between $3 \mathrm{~nm}$ and $20 \mathrm{~nm}[1,2]$. The gas phase contains argon (< 100 mbar), either fullerenes $\left(\sim 10^{-2}\right.$ mbar) or methane $(\sim 1$ mbar), and about 1 mbar hydrogen. The small amount of hydrogen tends to stabilize the plasma and has only minor effects on the properties of the films. PPNCD deposition from a fillerene / argon mixture entirely without added hydrogen has been dernonstrated [3]. One main difference of this type of plasma as compared to hydrogen-rich diamond PACVD is a high renucleation rate for new diamond crystals [4], which cause the nanograin structure. Deposition of PPNCD is performod in conventional microwave plasma systems for diamond PACVD. Proof of phase-purity was given by a variety of characterization methods including electron energy loss spectroscopy. The percentage of non-sp ${ }^{3}$ bonded C-atoms has been estimated to be between $3 \%$ and $10 \%$ reflecting the presence of $\pi$-bonded carbon at the grain boundaries [5]. 


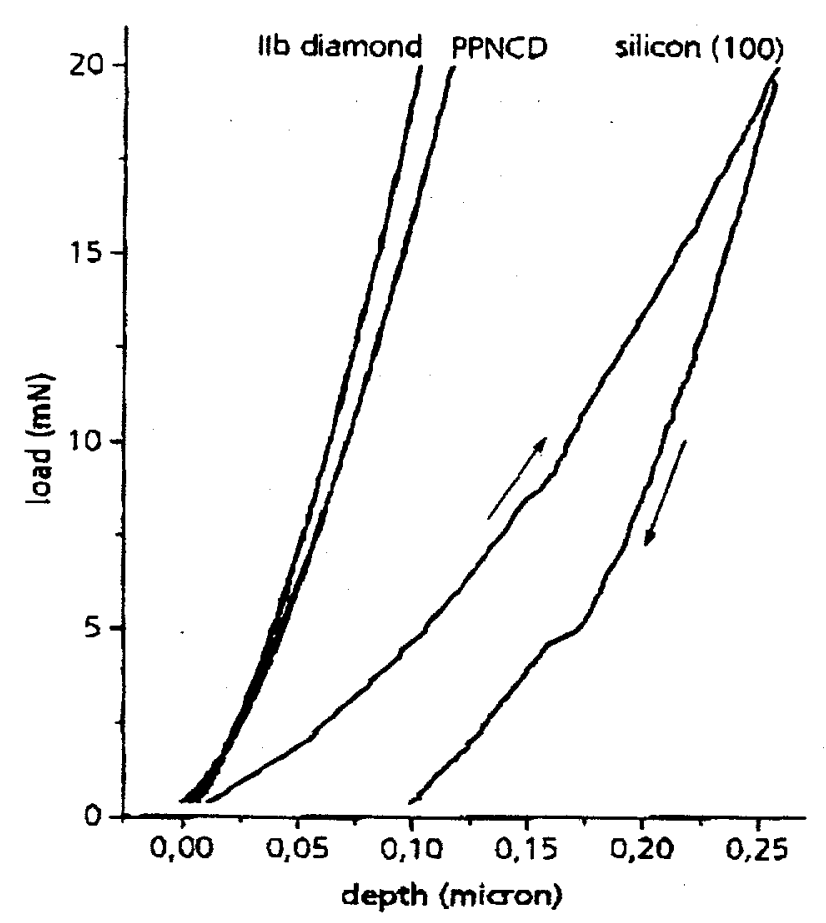

Fig. 1: Microindentor load-displacement curves of a synthetic IIb diamond (Sumitomo), a phase-pure nanocrytalline diamond (PPNCD) film (thickness 3 $\mu \mathrm{m})$ and a silicon (100) wafer.
PPNCD films show smooth surfaces, low friction coefficients, low wear, and low onset voltages for electron emission. They can be conformally coated on microstructured substrates. Potential applications are fluid pump seals, cold cathodes, microelectro-mechanical systems and machining of difficult-to-cut materials. In this paper, we present data about mechanical, acoustical, vibrational and electronical properties of PPNCD, and these are discussed within the highenergy grain boundary model advanced by Keblinski et al. [6].

\section{MECHANICAL PROPERTIES}

Microhardness characterization was performed with a Fisherscope $\mathrm{H} 100$ microindentor with which the displacement $h$ of a Vickers-type diamond has been recorded as a tiunction of its load P. The outermost end of the tip of the indentor has a curvature with a radius of about $0,5 \mu \mathrm{m}$ and an edge lingth parallel to the substrate of $0,2 \mu \mathrm{m}-0,5 \mu \mathrm{m}$. Thus, the lateral extensions of the indentations are at least a factor of ten larger than the size of the crystallites in the films. The maximal indentation depth $h$ was kept below $10 \%$ of the film thickness in order to avoid any influence of the substrate on the indentation. Since this is less than the curvature of the indentor, a qualitative deduction of the hardness

H by using the definition $H=P /\left(26,43 h^{2}\right)$ is not possible, even if the "indentation size effect" is considered [7,8]. Fig. 3 shows as-measured load-displacement curves of a nanocrystalline thin film gown from the $\mathrm{CH} 4 / \mathrm{H} 2 / \mathrm{Ar}$ gas mixture in comparison to a synthetic diamond(100) and silicon(100). The maximal load is 25 $\mathrm{mN}$ for all samples, yielding indentation depths of $116 \mathrm{~nm}, 102 \mathrm{~nm}$, and $250 \mathrm{~nm}$, respectively. All curves are the average of at least ten single measurements, however, scattering among them is very low. The elastic hardness of the PPNCD film is $78 \%$ of that of the synthetic diamond, assuming that the hardness is proportional to $1 / \mathrm{h}^{2}$. The film is thus superhard and fully elastic carbon. For comparison, the silicon sample in Fig. 1 exhibits strong plastic deformation and a displacement discontinuity below a loading of $10 \mathrm{mN}$, superhard carbon nitride thin films already exhibit a substantial plastic behavior at a loading of $5 \mathrm{mN}$ [9] and single crystalline (0001) Sapphire exhibits displacement discontinuities already below a loading of $15 \mathrm{mN}$ [10].

The PPNCD film shows the same total elastic recovery as the single crystalline diamond, i.e., the curves of penetration and release of the indentor are practically equal. Since the size of the indentor is much larger than the diameter of the individual grains of the nanocrystalline film, this total elasticity clearly demonstrates a high resistance against grain boundary sliding.

\section{ACOUSTIC PROPERTLES}

Elastic constants have been studied with a reflection-type scanning acoustic microscope (SAM 2000, KSI) at a fixed frequency of $1 \mathrm{GHz}$. The film is exposed to a perpendicularly impacting, focused acoustic wave, with the focus being below the surface. At the surface, this wave is partly transformed to a surface acoustic wave (SAW). This SAW backemits a acoustic wave into the space above the surface, where it interferes with the spocularly reflected wave. The microscope records the intensity of this interference (piez,o-crystal induced voltage $V$ ) as a function of the depth $z$ of the focus below the surface [11], yielding $V(z)$ plots. Fig. 2 shows the 


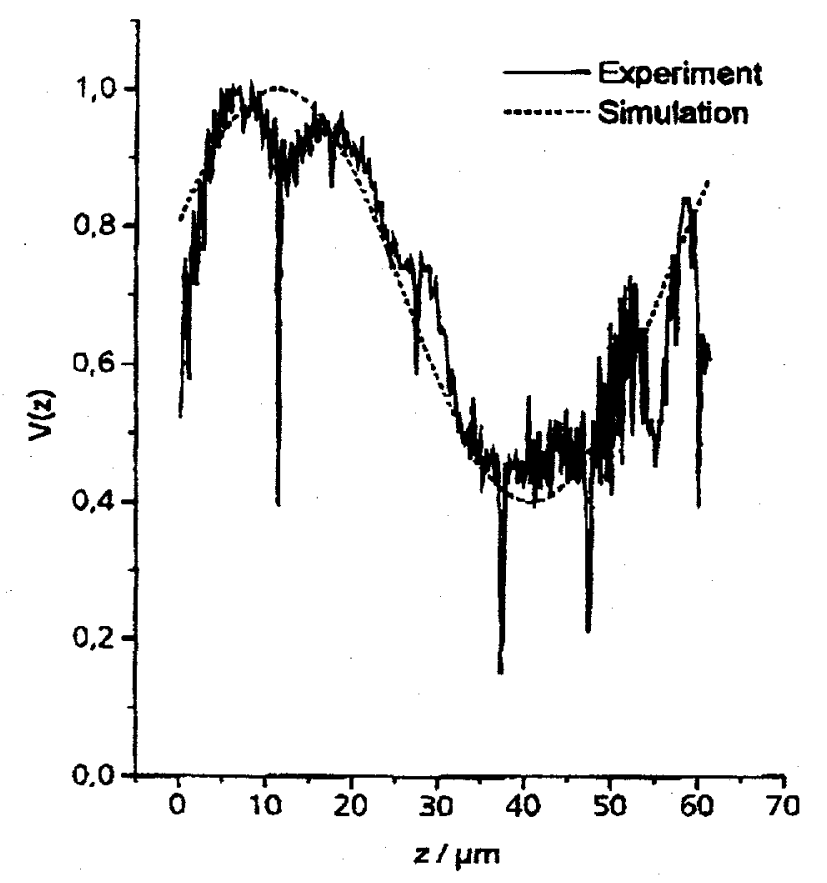

Fig. 2: Measured and simulated $V(z)$-curve for a 5 $\mu m$ thick phase-pure nanocrystalline diamond (PPNCD) film as obtained with a scanning acoustical microscope.

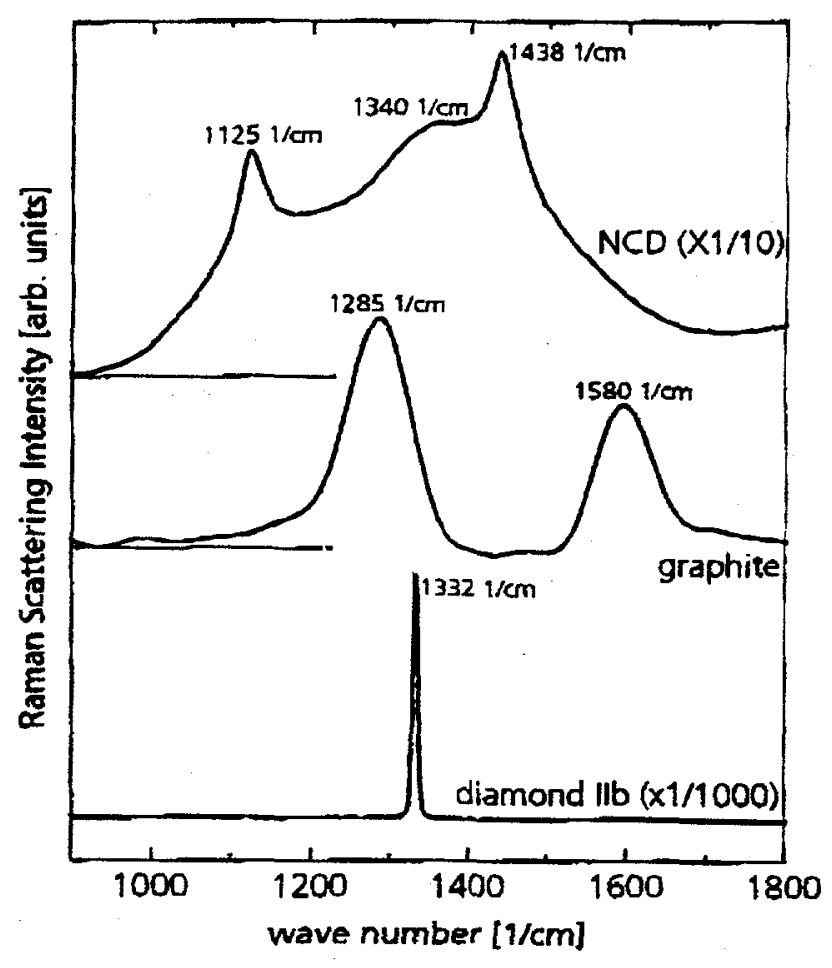

Fig. 3: Ramon spectra of a synthetic IIb diamond (Stomitomo), pyrolytic graphite and a $3 \mu \mathrm{m}$ thick phasepure nanocrystalline diamond (PPNCD) film. The excitation wavelength was $1064 \mathrm{~nm}$.

interference pattern obtained in this way for a $5 \mu \mathrm{m}$ thick PPNCD film. It shows a sine-like pattern, and the transversal velocity $v_{t}$ of the SAW can be calculated from the period of V(z) curve [12] to $10450 \mathrm{~m} / \mathrm{s}$.

Young's modulus $E$ and the shear modulus $G$ are related to $v_{t}$ through the equations $G=\rho v_{1}^{2}$ and $E=2(1+v)$ $G$. With the mass density $\rho=3,51 \mathrm{~g}_{\mathrm{cm}^{3}}$ and the and Poisson's ratio $v=0,107$ of diamond [13], these equations result in $\mathrm{G}=384 \mathrm{GPa}$ and $\mathrm{E}=864 \mathrm{GPa}$, which are close to crystal diamond $(\mathrm{G} \sim 354 \mathrm{GPa}$ to 535 GPa, E $1040 \mathrm{GPa}$ ).

\section{VIBRATIONAL PROPERTIES}

Raman spectroscopy is widely used for the characterization of diamond thin films because it allows the discrimination between totally $\mathrm{sp}^{3}$-bonded carbon, with a narrow phonon peak at $1332 \mathrm{l} / \mathrm{cm}$, and carbon with other bonding configurations and thus different Raman spectra. The relative strength of Raman scattering for differently bonded carbon is also strongly dependent on the excitation wavelength tue to electronic resonance effects; enhanced scattering is observed in the case of sp3-type bonds with high-energy excitation (UV-light) and in the case of sp ${ }^{2}$-type bonds with low-energy excitation (infrared light). Raman spectra of PPNCD films taken with excitation wavelengths in the visible and UV spectral regime exhibit a sharp phonon peak at 1332 $1 / \mathrm{cm}$ and a peak at $11251 / \mathrm{cm}$. A peak at about $11251 / \mathrm{cm}$ was also observed in nanocrystalline diamond samples grown in a $1 \% \mathrm{CH} 4 / 99 \% \mathrm{H}_{2}$ plasma at low substrate temperature $\left(650^{\circ} \mathrm{C}\right.$ ) and has been attributed to diamond crystal size effects on the Raman selection rules [14].

Fig. 3 shows Raman spectra taken from PPNCD, graphite powder and IIb-diamond, taken with a Fourier transform infrared spectrometer (Bruker IFS 66/S - FRA106) and excitation at $1064 \mathrm{~nm}$. Graphite shows the usual phonon peak at $1580 \mathrm{l} / \mathrm{cm}$ and disorder peak at $1285 \mathrm{l} / \mathrm{cm}$, and diamond the already mentioned peak at 


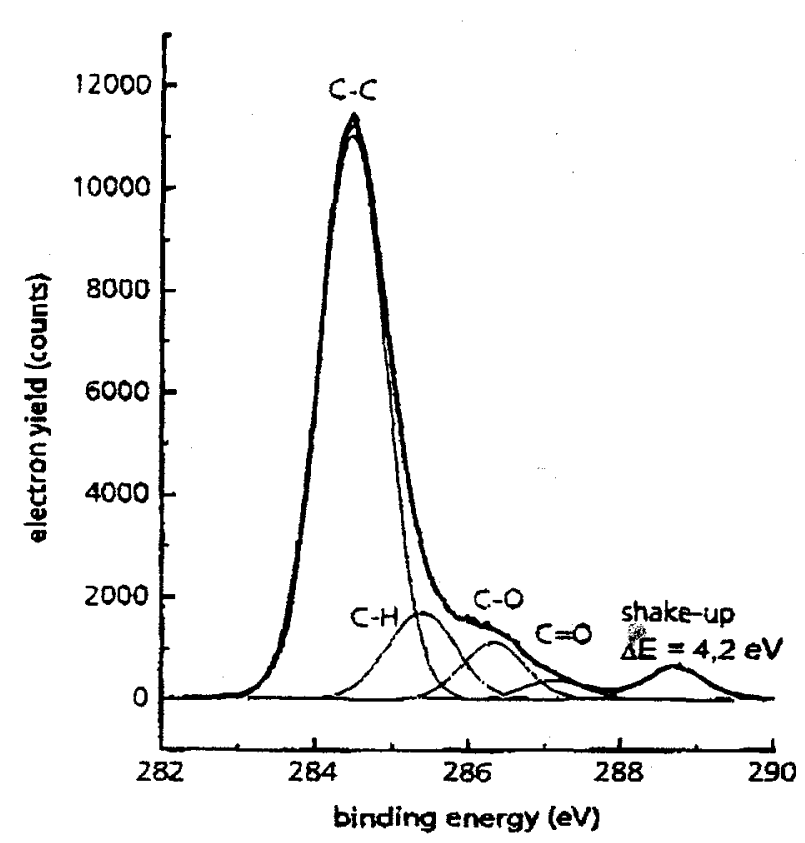

Fig. 4: X-ray photoelectron spectrum of a $3 \mu \mathrm{m}$ thick phase-pure nanocrystalline diamond (PPNCD) film for electron energies in the range of the Cls binding energy.
$1332 \mathrm{l} / \mathrm{cm}$. The PPNCD film apparently exhibits a superposition of three contributions: One peak at $1125 \mathrm{l} / \mathrm{cm}$ and a broad hump around 1340 $1 / \mathrm{cm}$, that we attribute to scattering by diamond as mentioned before. The third contribution is a peak at $14381 / \mathrm{cm}$. Peaks in between the phonon peaks of graphite and diamond are frequently observed in diamond PACVD films, however, they are normally located above $15001 / \mathrm{cm}$ and attributed to non-diamond carbon of $s p^{2}$ or mixod $\mathrm{sp}^{2} / \mathrm{sp}^{3}$ hybridization [15]. Yarbrough and Roy [16] reported Raman spectra of nanocrystalline diamond samples grown in a $1 \% \mathrm{CH}_{4} / 99 \% \mathrm{H}_{2}$ plasma (see also [14]). For grain sizes below 20 $\mathrm{nm}$, these contain a peak at $1460 \mathrm{1} / \mathrm{cm}$, in addition to peaks above $15001 / \mathrm{cm}$. The peak at $1460 \mathrm{l} / \mathrm{cm}$ they attribute to non-crystalline tetrahedrally bound carbon structures. The peak at $1438 \mathrm{l} / \mathrm{cm}$ in the present PPNCD spectrum may thus tentatively be assigned to Raman scattering at a carbon structure that contains $\mathbf{s p}^{2}$ and $\mathrm{sp}^{3}$ bonds, however, with an essentially higher $\mathrm{sp}^{3}$ character than the non-diamond structures in other PACVD diamond films. The absence of peaks at higher energy can be explained by the lack of an almost $\mathbf{s p}^{2}$ bonded

carbon network, referring to the fact, that the peaks above $1500 \mathrm{1} / \mathrm{cm}$ in graphite and many types of amorphous carbon are due to in-plane vibrations of mostly $\mathrm{sp}^{2}$ bonded carbon networks (the so-named Gpeak). The PPNCD Raman spectrum shown in Fig. 3 is thus consistent with a carbon structure, in which solitary carbon double bonds are embedded in an otherwise sp $p^{3}$ bonded carbon structure.

\section{ELECTRONIC PROPERTIES}

Any deviation from perfoct $\mathrm{sp}^{3}$ bonding should result in electronic states within the diamond band gap. Energy loss spectra of PPNCD samples taken in a high resolution transmission electron micrascope did not give evidence for an energy loss feature due to graphitic states [17], however this measurement does not disprove the existence of a small amount of non-diamond carbon. Fig. 4 shows a X-ray excited photoelectron spectrum of a PPNCD film in the binding epergy range of $C 1 s$ electrons, taken with a $A h_{k x}$ excitation radiation (ESCALAB 220i-XI, Vacuum Generators). The measured data have been corrected with respect to secondary electron emission [18] and thereafter decomposed into a superposition of five Gaussian profiles by means of a Levenberg-Marquardt-algorithm. The main peak at a binding energy of $284,5 \mathrm{eV}$ is due to all-carbon bonded carbon atoms. Its width amounts to $1,1 \mathrm{eV}$ and, since the energy difference betwoen differently hybridized $\mathrm{C}$ atoms is $\sim 0,3 \mathrm{eV}[18,19]$, it is not possible to identify non-diamond C-C bonds in this spectrum. The three peaks with an energy difference (chemical shift) with respect to the $\mathrm{C}-\mathrm{C}$ peak of $0,95 \mathrm{eV}, 1,8 \mathrm{eV}$ and $2,6 \mathrm{eV}$ are due to $\mathrm{C}-\mathrm{H}[20], \mathrm{C}-\mathrm{O}$ and $\mathrm{C}=\mathrm{O}[21]$, respectively. The presence of oxygen in addition to hydrogen is possibly due to the lack of a large excess of hydrogen during growth [22].

The final feature of this spectrum is the peak with an energy difference with respect to the C-C peak of $4.2 \mathrm{eV}$. Such a high chemical shift of $\mathrm{C} 1$ electrons appears only in extremely electronegative bonding situations like $\mathrm{N}$ C. 02 , which are very unlikely for PPNCD. 'The peak at $4.2 \mathrm{eV}$ is thus most likely due to excitation of C2sp clectrons into unfilled electronic states (shake-up loss). The corresponding shake-up loss of graphite is found at $6.3 \mathrm{eV}$ and assigned to $\pi \pi^{*}$ excitations $[23,24]$. The energy difference of $4,2 \mathrm{eV}$ is less than the diamond 
band gap of $5.2 \mathrm{eV}$, and the spectrum in Fig. 3 thus gives strong and direct evidence for the presence of electronic states within the diamond band gap, in accord with theoretical calculations [17].

\section{DISCUSSION}

The hardness and elastic moduli of PPNCD films rival single crystal diamond, whereas the vibrational and electronic properties exhibit distinct differences. The hardness of nanocrystalline materials is very much determined by their grain boundaries. In metals, when the grain size decreases below $20 \mathrm{~nm}$, a frequently observed softering has been attributed to grain boundary sliding [25], in that grain boundary sliding becomes increasingly easier with decreasing grain size (reverse Hall-Petch effect). In a similar way, grain boundary sliding is also recognized as the dominant mechanism for high-temperature creep in nanocrystalline ceramics [26]. The mechanical properties of the PPNCD films at room temperature as described above imply now, that grain boundary sliding is strongly inhibited even for nanocrystalline yrains and that the average intergranular bond of PPNCD is about of equal strength as the intragranular bond of single crystal diamond. This can be explained by covalent carbon bonds crosslinking the grains. The observed vibrational and electronic properties of PPNCD, that is the Raman peak at $14381 / \mathrm{cm}$ and the electronic shake-up loss of $4,2 \mathrm{eV}$, then indicate that the interyranular bonds are at least partly solitary double bonds. Such double bonds would be of higher binding energy than single bonds characteristic of the intragranular bonds. However, the grain boundary area specific density could be lower than the intragranular bond density, such that in total the adhesive grain boundary energy is similar to the cohesive energy of single crystal diamond.

The occurrence of double bonds in the grain boundaries is comprehensible owing to a proposed $\mathrm{C}_{2}$ nucleation mechanism. The mechanism involves insertion of $\mathrm{C}_{2}$ groups into the $\pi$-bonds of dimer rows of a reconstructed (100) surface. Total densities of states for both a $\pi$-bonded (double bonded) stacking fault and a $\Sigma 5$ twined grain boundary have been calculated using periodic density functional methods [17].

Until now there are no experimental indications that the relative crystallographic orientation of two adjacent grains in PPNCD show any orientational preferences, nor are there models to favor preferred orientations on the basis of energetic or molecular-kinetic considerations. Considering the large manifold of incommensurate and large-unit-cell grain boundaries of diamond, Keblinski et al. $[6,27]$ show, that high-angle twist boundaries of (100) planes are representatives for this manifold: The (111) and (110) twist boundaries are unique in that only $25 \%$ of the interface bonds involve atoms across the interface; all others including the (100) twist boundaries involve 50\%. According to their Monte-Carlo simulations, this has the consequence, that bighangle (100) twist boundaries are of higher stability than corresponding (111) and (110) boundaries due to the relatively large number of $\mathrm{sp}^{2}$ bonds connecting the grains in the (100) twist boundary. In principle, such highenergy grain boundaries can be mechanically stronger than even the perfect crystal. This result nicely explains the experimentally obtained high hardness and elastic constants as described above.

The consonance between these simulations and the present experimental work is even more striking, if we now consider the vibrational and electronic properties. According to the simulations, the $\mathrm{sp}^{2}$ coordinated atoms are rather poorty connected amongst themselves, thereby preventing the formation of graphite-like structures [6], in agreement with the observed Raman peak at $14381 / \mathrm{cm}$ and the lack of peaks above $1500 \mathrm{l} / \mathrm{cm}$. The local electronic density of a diamond (100) $\Sigma 29$ grain boundary as obtained from the simulation [27] show that the bonds in between the interface form a mixture of $\mathrm{sp}^{2}$ and $\mathrm{sp}^{3}$ bonds with electronic states within the diamond bad gap. Considering, that only $3 \%-10 \%$ of all carbon atoms are involved in the grain boundaries, the shakeup loss of $4,2 \mathrm{eV}$ can be due to an excitation of an electron out of a filled interface state into an unfilled interface state, or more likely, between interface states and states of the diamond crystals.

In summary, this work shows that the hardness and elastic properties of PPNCD rival single crystal diamond. In addition, those vibrational and electronic properties that are different from single crystal diamond are attributed to high energy grain boundaries with strong $\mathrm{sp}^{2}$ bonds connecting the grains. The experimental data are in good agreement with reported Monto-Carlo grain boundary simulations. 


\section{ACKNOWLEDGEMENT}

Sincere thanks are due to A. Steffen for his assistance for the microhardness measurements. The work supported by the German "Bundesministerium fuer Bildung, Wissenschaft, Forschung und Technology" (BMBF) under Contract No. 13N6630/9 and the State of Bremen under the auspices of the research program "Preparation, Properties and Reliability of Microstructured Composite Materials"; and by the U.S. Department of Energy, BES-Materials Sciences, under Contract W-31-109-ENG-38.

\section{REFERENCES}

[1] D.M. Gruen, S.Liu, A.R. Krauss, J. Luo and X.Pan, Appl. Phys.Lett. 64 (1994), p. 1504.

[2] D.M. Gruen, C.D. Zuiker, A.R. Krauss, and X.Pan, J.Vac.Sci.Technol. 13 (1995), p. 1628.

[3] H.-G. Busmann, U. Brauneck, H.-W. David, S. Diekhoff, and S. Boseck, in Proc. XI. Int. Winterschool on Electronic Properties of Novel Materials - Molecular Nanostructures, Eds. H. Kuzmany, J. Fink. M. Mehring and S. Roth, World Scientific Publishing Company, 1998, p. 500-505.

[4] D. Zhou, A.R.Krauss, T.D. Corrigan, T.G.McCauly, R.P.H. Chang, and D.M. Gruen, J.Electrochern. Soc. 144,8 (1997), p. L224.

[5] L.C. Qin, D. Zhou, A.R. Krauss and D.M. Gruen, Nanostructured Materials 10 (1998), p. 649.

[6] P. Keblinski, D. Wolf, S.R. Phillpot, H. Gleiter, J. Mater. Res. 13,8 (1998), p. 2077.

[7] M.F. Doerner, W.D. Nix, J. Mater. Res. 1 (1986), p. 601.

[8] H.-H. Behncke, Härtereitechnische Mittcilungen, Zeitschrift für Wärmebehandlungen und Werkstofftechnik, 48,5 (1993).

[9] S. Sjostrom, S. Stafstrơm, M. Boman, and J.-E. Sundgren, Pbys. Rev. Lett. 75,7 (1995), p. 1336.

[10] T. Page, W.C. Oliver and C.J. McHargue, J. Mater. Res. 7,2 (1992), p. 450.

[11] Z. Yu, S. Boseck, Rev. Mod. Phys. 67,4 (1995), p. 863.

[12] G.A.D. Briggs, Acoustic Microscopy, Clarendon, Oxford, 1992.

[13] J. E. Field, Properties of Diamond, Academic Press, New York, 1993.

[14] W.A. Yarbrough and R. Messier, Science 247 (1990), p. 688.

[15] C. Wild, N. Herres, J.Wagner, P.Koidl, T.R. Anthony, Proc. I" Int. Symp. on Diamond and DiamondLike Films, Eds. J.P. Dismukes et al., The Electrochemical Society, Pennigton, NJ, 1989, p. 283-295.

[16] W.A. Yarbrough and R. Roy, in Diamond and Diamond-Like Materials Synthesis, Eds. G.H. Johnson, A.R. Badzian, M.W. Geis, Materials Research Society, Pittburgh, PA, 1988, p.33.

[17] P. Zapol, L.A. Curtiss and D.M. Gruen, Mat. Res. Soc. Symp. Proc. Vol. 538 (1999), p. 371.

[18] J.F. Morar, F.J. Himpsel, G. Hollinger, J.L. Jordan, G. Hughes, F.R. Feeley, Phys. Rev. B 33,2 (1986), p. 1340.

[19] S.C. Sharma, M. Green, R.C. Hyer, C.A. Dark, T.D. Black, A.R. Chourasia, D.R. Chopra, K.K. Mishra, J. Mater. Res. 5,11 (1990), p. 2424.

[20] B.B. Pate, Surf. Sci. 165 (1986), p. 83.

[21] High Resolution XPS of Organic Polymers, The Scientific ESCA 300 Database, John Wiley \& Sons.

[22] H.-G. Busmann, U. Brauneck, and H.-W. David, Carbon 36 (1998), p. 529.

[23] S.R. Kasi, H. Hang, J.W. Rabalais, J. Vac. Sci. Technol. A6 (1988), p. 1788.

[24] D. Ugolini, J. Eitle, P. Oelhafen,J. Appl. Phys. A54 (1992), p. 57-60.

[25] J. Schioz, F.D. Di Tolla, K.W. Jacobsen, Nature, 391 (1998), p. 561.

[26] Nanomaterials: Synthesis, Properties and Applications, Eds. A.S. Edelstein, R.C. Cammarata, Institute of Physics Publishing, Bristol and Philadejphia, 1996.

[27] P. Keblinski, D. Wolf, F. Cleri, S.R. Phillpot, H. Gleiter, MRS Bulletin, 23,9( 1998), p. 36. 